\title{
Molusco contagioso - intervenção terapêutica na idade pediátrica. Revisão Baseada na Evidência.
}

Maria Ana Gaspar, Ana Filipe Pinheiro, ** Ana Sanches***

\section{RESUMO}

Introdução: O molusco contagioso é uma doença infecciosa viral cutânea frequente em crianças, ocorrendo tipicamente entre os 2 e os 5 anos de idade. Na maioria dos casos a doença é autolimitada e resolve entre 6 meses a 2 anos, mas nalguns casos persiste por 5 anos. A intervenção terapêutica pretende aliviar a sintomatologia, controlar a disseminação das lesões, prevenir o aparecimento de cicatrizes ou infecções bacterianas secundárias, e pode ainda ser utilizada por motivos cosméticos e sociais.

Objectivo: Determinar a evidência existente sobre a eficácia terapêutica e os eventuais efeitos adversos das intervenções terapêuticas no molusco contagioso na idade pediátrica, em crianças imunocompetentes.

Fontes de dados: Bases de dados Medline, Cochrane Library, Dynamed, National Guideline Clearinghouse e Evidence Based Medicine Guidelines.

Métodos de revisão: Pesquisa de normas de orientação clínica (NOC), revisões sistemáticas (RS), metanálises (MA) e ensaios clínicos aleatorizados (ECA), publicados entre Janeiro de 2001 e Setembro de 2011, em português, inglês, francês e espanhol, com limite de idade $\leq 18$ anos, utilizando o termo MeSH molluscum contagiosum. Foram critérios de exclusão na selecção dos artigos o molusco contagioso de transmissão sexual e em crianças imunodeprimidas. Para avaliar o nível de evidência foi utilizada a escala SORT (Strength of Recommendation Taxonomy) da American Family Physician.

Resultados: Foram encontrados 22 artigos, tendo sido seleccionados duas normas de orientação clínica, uma revisão sistemática, um sumário da Dynamed e um ensaio clínico aleatorizado. Há evidência da eficácia com reduzidos efeitos adversos para a terapêutica tópica com extracto de folha mirtilo-limão ou com curetagem (força de recomendação B). Relativamente às terapêuticas tópicas com peróxido de benzoílo, imiquimod e cantaridina, a sua evidência é menor, bem como com a terapêutica sistémica com cimetidina e a destrutiva física com crioterapia (força de recomendação C). As restantes terapêuticas estudadas não apresentam evidência de eficácia suficiente para se emitir recomendação.

Conclusões: Os resultados obtidos apresentam evidência limitada para a recomendação de intervenção terapêutica no molusco contagioso na idade pediátrica. São necessários mais estudos bem desenhados, prospectivos, sobre as diferentes opções terapêuticas versus placebo ou versus atitude expectante. Na ausência de evidência robusta sobre a eficácia e segurança dos tratamentos, deve ser considerada a atitude expectante.

Palavras-chave: Molusco Contagioso; Terapêutica.

\section{INTRODUÇÃO}

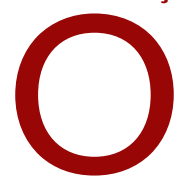

molusco contagioso é uma doença infecciosa viral cutânea muito frequentemente encontrada em crianças. A infecção é causada pelo vírus do molusco contagioso, com dupla

\footnotetext{
*Interna de Medicina Geral e Familiar, UCSP dos Olivais, ACES II de Lisboa Oriental **Interna de Medicina Geral e Familiar, USF de São João Evangelista dos Lóios, ACES Il de Lisboa Oriental
}

***Interna de Medicina Geral e Familiar, UCSP da Lapa, ACES III de Lisboa Central cadeia de ácido desoxirribonucleico, pertencente à família dos poxvirus (Poxviridae), género Moluscipox. ${ }^{1,2}$

A transmissão ocorre através de contacto directo com a pessoa infectada, através de fomitos ou por autoinoculação. ${ }^{3} \mathrm{O}$ período de incubação varia de catorze dias a seis meses. A duração das lesões é muito variável e o intervalo intercrítico também. São frequentes as recorrências e, apesar de na maioria dos casos (de crianças previamente saudáveis) a doença ser autolimitada e resolver entre seis me- 
ses a dois anos, nalguns casos persiste por cinco anos. ${ }^{1,2} \mathrm{O}$ risco de transmissão é inferior a $10 \%{ }^{4}$

A infecção é rara em crianças com menos de 1 ano de idade, ocorrendo tipicamente entre os 2 e os 5 anos de idade. ${ }^{1,2}$

O diagnóstico baseia-se na apresentação clínica, podendo a biópsia ser realizada em casos de incerteza e atipia, mais frequentemente em imunodeprimidos. ${ }^{2}$ Clinicamente apresenta-se com pápulas únicas ou múltiplas (normalmente em número não superior a 20), indolores, esféricas, brilhantes, peroladas, que classicamente apresentam uma umbilicação central. $\mathrm{O}$ seu tamanho varia de $1 \mathrm{~mm}$ a $1 \mathrm{~cm}$ de diâmetro. As lesões podem ser pruriginosas. Também existe uma variante do molusco contagioso de transmissão sexual, mais frequentemente encontrada em adolescentes e adultos com vida sexual activa, que ocorre nas regiões genital, perineal, púbica e pele circundante. ${ }^{1-3}$

As crianças imunodeprimidas estão particularmente vulneráveis à infecção por molusco contagioso, apresentando frequentemente múltiplas lesões, em áreas atípicas (como face e pescoço) e mais resistentes à terapêutica. ${ }^{1}$

Casos de atopia (como o eczema atópico) parecem ter uma maior incidência da infecção por este vírus. Actualmente mais crianças apresentam lesões de molusco contagioso, provavelmente associado a um aumento do número de crianças com atopia. Nestas há tendência para o aparecimento de lesão eczematosa que se desenvolve em redor da lesão do molusco. ${ }^{1}$

O molusco contagioso é um motivo de consulta frequente em Medicina Geral e Familiar, particularmente na idade pediátrica. Autores defendem que o médico de família deverá estar apto a lidar com esta situação, devendo referenciar aos cuidados de saúde secundários os casos com numerosas lesões (superior a 50), com localização peri-ocular ou lesões resistentes à terapêutica. ${ }^{4}$

Sendo o molusco contagioso uma doença autolimitada em crianças imunocompetentes, a atitude expectante deve ser considerada. ${ }^{1-6}$ Existe, no entanto, uma grande variedade de opções terapêuticas. Estas podem ser divididas em três categorias principais: (a) aplicação de agentes tópicos (terapêutica tópica), (b) tratamento sistémico (terapêutica sistémica) e (c) destruição física das lesões (terapêutica destrutiva física). ${ }^{1,2}$

O início de terapêutica pretende acelerar o processo de resolução das lesões, procurando aliviar o desconforto (como por exemplo o prurido), controlar a disseminação das lesões (nomeadamente por autoinoculação), prevenir o aparecimento de cicatrizes ou infecções bacterianas se- cundárias, e, ainda, ser utilizada por motivos cosméticos e sociais. Muitas crianças são excluídas de actividades escolares e de lazer, sendo estigmatizadas pela sociedade por apresentarem lesões de molusco contagioso. Para os pais também constitui uma situação de grande ansiedade e sofrimento. ${ }^{1,3}$

Contudo, as bases científicas para o início de uma intervenção terapêutica permanecem pouco claras, colocando, consequentemente, aos médicos, dúvidas sobre a melhor decisão a tomar em termos de início ou não de tratamento activo bem como sobre a melhor estratégia terapêutica. ${ }^{1}$

Pretende-se, assim, realizar uma revisão da evidência encontrada sobre as estratégias de intervenção terapêutica no molusco contagioso na idade pediátrica, no que se refere a eficácia do tratamento (resolução completa ou parcial) e eventuais efeitos adversos.

\section{MÉTODOS}

Foi realizada uma pesquisa bibliográfica desde Janeiro de 2001 a Setembro de 2011 nas seguintes bases de dados: Medline, Cochrane Library, Dynamed, National Guideline Clearinghouse e Evidence Based Medicine Guidelines. Foram pesquisadas normas de orientação clínica (NOC), revisões sistemáticas (RS), metanálises (MA) e ensaios clínicos aleatorizados (ECA) em português, inglês, francês e espanhol, com limite de idade menor ou igual a 18 anos, utilizando o termo MeSH molluscum contagiosum. Foram excluídos artigos relativos a molusco contagioso transmitido sexualmente e molusco contagioso em crianças com imunodeficiência.

Foi aplicada a escala Strength of Recommendation $\mathrm{Ta}$ xonomy $(\mathrm{SORT})^{7}$ da American Family Physician para classificar em níveis de evidência e forças de recomendação. Segundo esta taxonomia, a qualidade do estudo está subdividida em três Níveis de Evidência (Nível de Evidência 1: estudos de boa qualidade, evidência orientada para o doente; Nível de Evidência 2: estudos de qualidade limitada, evidência orientada para o doente; Nível de Evidência 3: outra evidência) e a Força de Recomendação em três graus (Força de Recomendação A: consistente, evidência orientada para o doente; Força de Recomendação B: inconsistente ou qualidade limitada, evidência orientada para o doente; Força de Recomendação C: consensos, evidência orientada para a doença).

\section{RESULTADOS}

Foram encontrados 22 artigos, tendo sido selecciona- 
dos duas normas de orientação clínica e três artigos: uma revisão sistemática, um sumário da Dynamed e um ensaio clínico aleatorizado. Dos 22 artigos encontrados, 17 eram ensaios clínicos, dos quais apenas foi seleccionado um, porque 11 já estavam incluídos na revisão sistemática, dois não se encontravam disponíveis (após contacto com as editoras das respectivas revistas), dois eram referentes a crianças com vírus da imunodeficiência humana e o último apresentava o abstract em inglês mas o artigo só estava disponível em chinês.

\section{Terapêutica Tópica}

\subsection{Normas de Orientação Clínica}

A National Guideline Clearinghouse emitiu uma norma de orientação clínica Management of molluscum contagiosum (2008), ${ }^{4}$ fazendo referência a duas intervenções terapêuticas tópicas: imiquimod e cantaridina. Relativamente ao imiquimod, a aplicação deste em creme $1 \%$ ou $5 \%$ três vezes por semana até o máximo de 16 semanas, com lavagem das áreas tratadas 6-10 horas depois da aplicação, estimula a imunidade celular ajudando na regressão do molusco contagioso. Foi atribuído um grau de recomendação B. No que refere à cantaridina $0,7 \%-0,9 \%$, a aplicação desta, uma vez por semana, com lavagem 2-4 horas após o tratamento com água abundante, é apontada com uma força de recomendação B. Para o caso da cantaridina, a sua aplicação está contraindicada na face e deve ser evitada no caso de mais do que 20 lesões de molusco contagioso.

Na Evidence Based Medicine Guidelines (2009) ${ }^{5}$ não há referência expressa a nenhuma terapêutica tópica específica, referindo-se de uma forma geral às terapêuticas tópicas como apresentando eficácia incerta no tratamento do molusco contagioso. (Quadro I)

\subsection{Revisão Sistemática}

Na Revisão sistemática da Cochrane, ${ }^{1}$ são incluídos onze ensaios clínicos. (Quadro II) Destes, oito estudos são descritos como aleatorizados (Antony 2001, ${ }^{8}$ Bazza 2007, ${ }^{9}$ Burke 2004, ${ }^{10}$ Hanna 2006, ${ }^{11}$ Leslie 2005, ${ }^{12}$ Saryazdi 2004, ${ }^{13}$ Short $2006{ }^{14} \mathrm{e}$ Theos $2004^{15}$ ), no entanto a forma como foi concebida a sequência de aleatorização só é descrita em três estudos
(Burke 2004, ${ }^{10}$ Hanna $2006^{11}$ e Leslie 2005 ${ }^{12}$ e e apenas cinco estudos estão descritos como duplamente cegos. Em dois estudos (Hanna $2006^{11}$ e Saryazdi $2004^{13}$ ) não são especificadas as desistências, verificando-se uma percentagem de desistência nos restantes ensaios que variou entre $5 \%$ (Short 2006 ${ }^{14}$ ) e 50\% (Antony 2001 ${ }^{8}$ ). Apenas seis estudos fazem comparação com placebo/veículo e nenhum compara com a atitude expectante. No geral também são estudos de pequenas dimensões, sendo o maior estudo com 124 crianças (Hanna $2006^{11}$ ), mas dividido por quatro braços.

No que refere à terapêutica tópica, esta é estudada em sete dos onze ensaios incluídos na revisão sistemática (Bazza 2007, ${ }^{9}$ Burke 2004, ${ }^{10}$ Hanna 2006,,${ }^{11}$ Leslie 2005, ${ }^{12}$ Saryazdi $2004,{ }^{13}$ Short $2006,{ }^{14}$ Theos $2004^{15}$ ).

No estudo Bazza $2007^{9}$ é comparada a aplicação de hidróxido de potássio creme $5 \%$ com uma solução salina estéril, cujas intervenções são aleatoriamente seleccionadas para serem aplicadas numa das metades (lado direito ou lado esquerdo) do corpo da criança. Cerca de $30 \%$ dos casos abandonaram o estudo e os resultados não mostraram diferença estatisticamente significativa em termos de resolução após 12 semanas: as duas intervenções obtiveram resolução completa em $85 \%$ dos casos.

A mesma comparação foi feita no estudo Short 2006, ${ }^{14}$ $2002^{16}$. O tratamento com hidróxido de potássio creme $10 \%$ levou a resolução completa após três meses de tratamento, de $70 \%$ dos casos comparativamente aos $20 \%$ tratados com solução salina, diferença considerada não estatisticamente significativa.

No estudo Theos 2004, ${ }^{15}$ comparou-se a aplicação de Imiquimod creme $5 \%$ versus o veículo creme. A resolução completa ocorreu às quatro semanas com o Imiquimod em duas

\begin{tabular}{|c|c|c|c|}
\hline NOC & Ano & Conclusões & NE \\
\hline $\begin{array}{l}\text { National Guideline } \\
\text { Clearinghouse }\end{array}$ & 2008 & $\begin{array}{l}\text { Aplicação de imiquimod creme } 1 \% \text { ou } 5 \% \text { três } \\
\text { vezes por semana, no máximo de } 16 \text { semanas } \\
\text { (atribuída força recomendação B) } \\
\text { Aplicação de cantaridina creme } 0,7 \%-0,9 \% \text {, } \\
\text { uma vez por semana (atribuída força } \\
\text { recomendação C) }\end{array}$ & 3 \\
\hline EBM Guidelines & 2009 & $\begin{array}{l}\text { Terapêuticas tópicas no tratamento do } \\
\text { molusco contagioso. (Eficácia incerta) }\end{array}$ & 1 \\
\hline
\end{tabular}

Legenda: EBM - Evidence Based Medicine; NE - Nível de evidência 


\begin{tabular}{|c|c|c|c|c|c|}
\hline Estudos & Tipo & Intervenção e amostra & Idades & Resultados & NE \\
\hline Bazza 2007* & $\begin{array}{l}\text { ECA, } \\
\text { duplamente } \\
\text { cego }\end{array}$ & $\begin{array}{l}\text { Hidróxido de potássio creme } 5 \% \text { vs } \\
\text { solução salina } \\
\mathrm{N}=30\end{array}$ & $\begin{array}{l}2-12 \\
\text { anos }\end{array}$ & $\begin{array}{l}\text { Resolução completa após } 12 \text { semanas } \\
\text { de tratamento. } \\
\text { (RR1,0,95\% IC, } 0,77-1,30, p=0,50)\end{array}$ & 2 \\
\hline $\begin{array}{l}\text { Short } \\
2002,2006 *\end{array}$ & $\begin{array}{l}\text { ECA, } \\
\text { duplamente } \\
\text { cego }\end{array}$ & $\begin{array}{l}\text { Hidróxido de potássio creme } 10 \% \text { vs } \\
\text { solução salina } \\
\mathrm{N}=20\end{array}$ & $\begin{array}{l}2-12 \\
\text { anos }\end{array}$ & $\begin{array}{l}\text { Resolução completa no final de } 3 \\
\text { meses. } \\
\qquad(\text { RR3,5, 95\% IC, 0,95-12,9, } p=0,50)\end{array}$ & 2 \\
\hline Theos 2004* & $\begin{array}{l}\text { ECA, } \\
\text { duplamente } \\
\text { cego }\end{array}$ & $\begin{array}{l}\text { Imiquimod creme } 5 \% \text { vs veículo } \\
\text { (controlo) } \\
\mathrm{N}=23\end{array}$ & $\begin{array}{l}1-9 \\
\text { anos }\end{array}$ & $\begin{array}{l}\text { Resolução completa: } \\
-4^{\mathrm{a}} \text { semana } \\
\text { (RR } 4,62,95 \% \mid C, 0,25-86,72, p=0,31 \text { ) } \\
-12^{\mathrm{a}} \text { semana } \\
\text { (RR3,67, 95\% IC, } 0,48-28,60, p=0,21 \text { ) }\end{array}$ & 2 \\
\hline $\begin{array}{l}\text { Hanna 2006* } \\
(* *)\end{array}$ & $\begin{array}{l}\text { ECA, não } \\
\text { duplamente } \\
\text { cego }\end{array}$ & $\begin{array}{l}4 \text { braços: } \\
1 \text { - curetagem } \\
2 \text { - cantaridina } 0,7 \% \\
3 \text { - ácido salicílico } 16,7 \% \\
4 \text { - imiquimod } 5 \% \\
\mathrm{~N}=124\end{array}$ & $\begin{array}{l}1-16 \\
\text { anos }\end{array}$ & $\begin{array}{l}\text { Resolução completa: } \\
\qquad \begin{array}{l}\text { Após } 1 \text { tratamento: } \\
\text { A } 002)\end{array} \\
\text { - curetagem: } 81 \% \\
\text { - cantaridina: } 37 \% \\
\text { - ác. salicílico: } 54 \% \\
\text { - imiquimod: } 55 \% \\
\text { Efeitos adversos: }(p<0,001) \\
\text { - curetagem: } 5 \% \\
\text { - cantaridina: } 19 \% \\
\text { - ác. salicílico: } 54 \% \\
\text { - imiquimod: } 27 \%\end{array}$ & 2 \\
\hline Leslie $2005^{*}$ & $\begin{array}{l}\text { ECA, não } \\
\text { duplamente } \\
\text { cego }\end{array}$ & $\begin{array}{l}3 \text { braços: } \\
1 \text { - ácido salicílico } 12 \% \\
2 \text { - fenol } 10 \% \text { em álcool } 70 \% \\
3 \text { - veículo (álcool } 70 \% \text { ) } \\
\mathrm{N}=114\end{array}$ & $\begin{array}{l}1-15 \\
\text { anos }\end{array}$ & $\begin{array}{l}\text { Resolução completa (até o período } \\
\text { máximo de } 6 \text { meses): } \\
\quad \text { - Ác. salicílico vs álcool } \\
\text { (RR1,28, } 95 \% \text { IC. } 0,81-2,02, p=0,30) \\
\quad \text { - Ác. salicílico vs fenol } \\
\text { (RR1,37, 95\% IC, } 0,86-2,17, p=0,18) \\
\text { - Fenol vs álcool } \\
\text { (RR0,93, 95\% IC, } 0,56-1,56, p=0,79)\end{array}$ & 2 \\
\hline $\begin{array}{l}\text { Saryazdi } \\
2004^{*}\end{array}$ & $\begin{array}{l}\text { ECA, não } \\
\text { duplamente } \\
\text { cego }\end{array}$ & $\begin{array}{l}\text { Peróxido de benzoílo creme } 10 \% \text { vs } \\
\text { tretinoína creme } 0,05 \% \\
\mathrm{~N}=23\end{array}$ & ne & $\begin{array}{l}\text { Resolução completa às } 6 \text { semanas } \\
(\text { RR } 2,20,95 \% I C ~ 1,01-2,79, p=0,047)\end{array}$ & 2 \\
\hline Burke 2004* & $\begin{array}{l}\text { ECA, } \\
\text { duplamente } \\
\text { cego }\end{array}$ & $\begin{array}{l}\text { Óleo mirtilo-limão } 10 \% \text { vs veiculo } \\
\text { (óleo) } \\
\mathrm{N}=31\end{array}$ & $\begin{array}{l}4-6 \\
\text { anos }\end{array}$ & $\begin{array}{l}\text { Resolução completa ou de } 90 \% \text { das } \\
\text { lesões } \\
\qquad \begin{array}{l}\text { (RR } 17,88,95 \% \text { IC } 1,13-282,72 \\
\text { p }=0,041)\end{array}\end{array}$ & 2 \\
\hline
\end{tabular}




\begin{tabular}{|c|c|c|c|c|c|}
\hline Estudos & Tipo & Intervenção e amostra & Idades & Resultados & $\mathrm{NE}$ \\
\hline $\begin{array}{l}\text { Al Mutairi } \\
2010\end{array}$ & $\begin{array}{l}\text { ECA, } \\
\text { duplamente } \\
\text { cego** }\end{array}$ & $\begin{array}{l}\text { Imiquimod creme } 5 \% \text { vs crioterapia } \\
N=74\end{array}$ & $\begin{array}{l}2-12 \\
\text { anos }\end{array}$ & 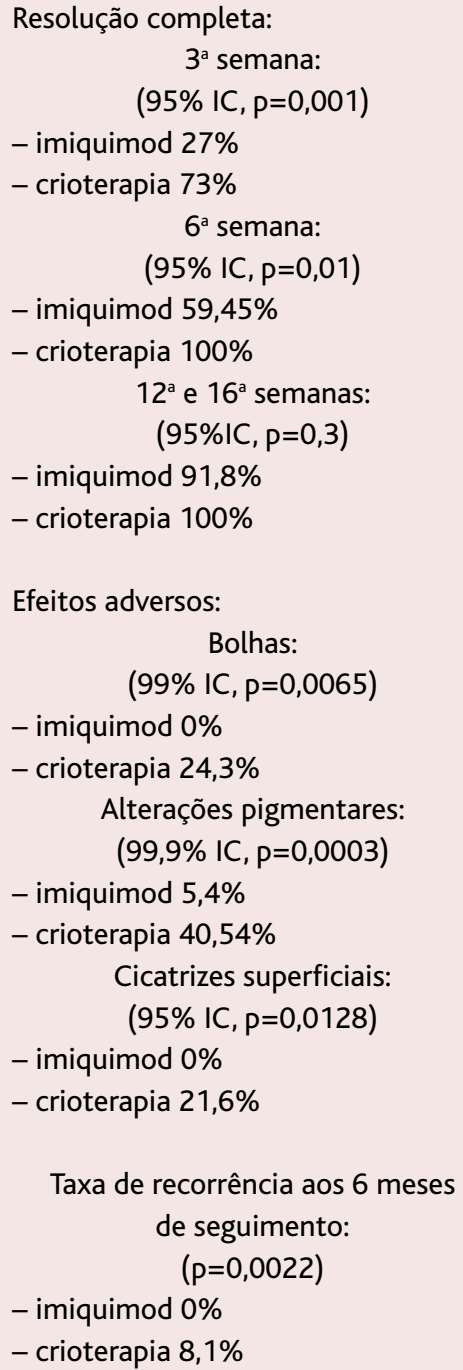 & 2 \\
\hline
\end{tabular}

Legenda: ECA - ensaio clínico aleatorizado; NE - Nível de evidência; ne - não especificado RR - Risco Relativo IC - Intervalo de confiança

* Ensaios clínicos incluídos na revisão sistemática

** Estudos que tratam também de terapêuticas destrutivas físicas

crianças e até às doze semanas em outras quatro crianças, tendo o controlo apenas uma resolução completa às 12 semanas. A resolução parcial também foi superior com o imiquimod (50\% e $67 \%$ das crianças tratadas com imiquimod com resolução parcial na $4^{\mathrm{a}}$ e $12^{\mathrm{a}}$ semanas, respectivamente versus controlo com $0 \%$ e $18 \%$ na $4^{\text {a }}$ e $12^{\mathrm{a}}$ semanas). As diferenças não foram estatisticamente significativas.
Quando foi comparada a aplicação de óleo mirtilo-limão $10 \%$ com controlo (veículo com cheiro a limão) durante três semanas, verificou-se uma resolução completa em $31 \%$ dos casos e resolução de $90 \%$ das lesões em $56 \%$ dos casos com óleo mirtilo-limão (versus $0 \%$ do controlo). Estas diferenças foram estatisticamente significativas. Três crianças apresentaram apenas um eritema moderado com 
a aplicação de óleo mirtilo-limão, sem queixas de desconforto (Burke 2004 ${ }^{10}$ ).

Já no estudo Leslie 2005, ${ }^{12}$ compararam-se as três intervenções: ácido salicílico $12 \%$ duas vezes por semana, fenol $10 \%$ em álcool $70 \%$ uma vez mensalmente e veículo (álcool $70 \%$ ) uma vez mensalmente. Completaram o estudo $73 \%$ das crianças, com resolução completa no período máximo de 6 meses de 87,5\% dos casos com o ácido salicílico, $56,3 \%$ com fenol e 59,2\% com veículo. As diferenças encontradas não foram estatisticamente significativas.

O estudo Hanna $2006^{11}$ comparou quatro intervenções: curetagem, cantaridina, ácido salicílico e imiquimod creme $5 \%$. A frequência dos tratamentos variou entre as intervenções, não havendo referência quanto à duração do tratamento até à resolução, tendo a eficácia sido determinada de acordo com o número de tratamentos necessários até à resolução completa. Com um valor de p de 0,002, a curetagem foi a intervenção mais eficaz, com resolução completa em $81 \%$ dos casos com apenas um tratamento. Também foi a intervenção que apresentou menos efeitos adversos $(\mathrm{p}<0,001)$.

A aplicação de peróxido de benzoílo creme $10 \%$ resultou em resolução completa após seis semanas em $73 \%$ dos casos versus $33 \%$ dos casos que aplicaram tretinoína creme $0,05 \%$. A diferença foi estatisticamente significativa (Saryazdi 2004). ${ }^{13}$

\subsection{Ensaio clínico aleatorizado}

O estudo Al Mutairi 2010,17 que não estava incluído na revisão sistemática, comparou a intervenção com imiquimod creme $5 \%$ aplicado cinco vezes por semana com crioterapia aplicada uma vez por semana, até à resolução completa ou até atingir o período máximo de 16 semanas. Foram realizadas avaliações semanais durante todo o período de tratamento e as crianças foram acompanhadas durante seis meses após cura clínica, para avaliação das recorrências. Todas as crianças cumpriram todo o período de tratamento. Verificou-se que na $3^{\mathrm{a}} \mathrm{e} 6^{\mathrm{a}}$ semanas a crioterapia foi mais eficaz que o imiquimod, diferenças estatisticamente significativas. Na $12^{\mathrm{a}} \mathrm{e} 16^{\mathrm{a}} \mathrm{se}$ manas, no grupo do imiquimod houve resolução completa em $91,8 \%$ e $100 \%$ versus o grupo da crioterapia com $100 \%$ dos casos desde a $6^{a}$ semana. As diferenças encontradas nas $12^{\mathrm{a}}$ e $16^{\mathrm{a}}$ semanas não foram estatisticamente significativas. A crioterapia foi mais rapidamente eficaz do que o imiquimod, mas a partir da $12^{\text {a }}$ semana de tratamentos foram as duas intervenções igualmente eficazes. No entanto a crioterapia apresentou efeitos adversos mais frequentes, com diferenças estatisticamente significativas no que se refere a bolhas, alterações pigmentares da pele e cicatrizes superficiais. Aos seis meses de seguimento observaram-se três recorrências $(8,1 \%)$ no grupo da crioterapia versus nenhuma no grupo tratado com imiquimod (Estudo com nível de evidência 2). (Quadro II)

\section{Terapêutica Sistémica}

\subsection{Normas de Orientação Clínica}

A norma de orientação clínica da National Guideline Clearinghouse (2008) ${ }^{4}$ refere que a toma de cimetidina 30$50 \mathrm{mg} / \mathrm{kg} /$ dia (distribuída por três tomas diárias), durante três meses, estimula a imunidade celular pelo aumento de linfócitos $\mathrm{CD} 4$, contribuindo para a regressão do molusco (atribuída força de recomendação C). São vários os efeitos adversos, nomeadamente, naúseas, vómitos, diarreia, dor abdominal, boca seca, cefaleias e tonturas. (Quadro III)

\subsection{Revisão Sistemática}

O estudo Antony 2001, ${ }^{8}$ incluído na revisão sistemática, compara a terapêutica com cimetidina suspensão oral $35 \mathrm{mg} / \mathrm{kg} / \mathrm{dia}$ com placebo. Este ensaio clinico apresentou $50 \%$ de desistências. Foi observada uma resolução completa aos quatro meses em $50 \%$ dos casos com cimetidina versus $46 \%$ dos casos com placebo, uma diferença não estatisticamente significativa. (Quadro IV)

\section{Terapêutica destrutiva física}

\subsection{Normas de Orientação Clínica}

A norma de orientação clínica da National Guideline

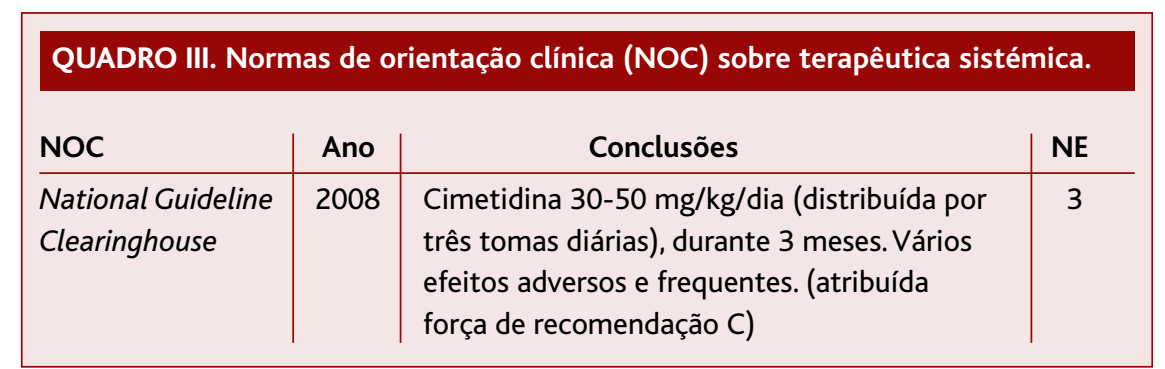

Legenda: NE - Nível de evidência 


QUADRO IV. Estudos sobre terapêutica sistémica.
\begin{tabular}{l|l|l|l|l|c|}
\hline Estudos & Tipo & Intervenção e amostra & Idades & \multicolumn{1}{|c|}{ Resultados } & NE \\
\hline Antony 2001* & $\begin{array}{l}\text { ECA, } \\
\text { duplamente } \\
\text { cego }\end{array}$ & $\begin{array}{l}\text { Cimetidina, per os, } \\
35 \mathrm{mg} / \mathrm{kg} / \text { dia vs placebo } \\
\mathrm{N}=38\end{array}$ & $\begin{array}{l}1-16 \\
\text { anos }\end{array}$ & $\begin{array}{l}\text { Resolução completa aos } 4 \text { meses } \\
\text { (RR1,10, 95\%IC 043-2,84, } \mathrm{p}=0,84)\end{array}$ & 2 \\
\end{tabular}

Legenda: ECA - ensaio clínico aleatorizado; NE - Nível de evidência; ne - não especificado RR - Risco Relativo IC - Intervalo de confiança

* Ensaios clínicos incluídos na revisão sistemática

$\begin{aligned} & \text { QUADRO V. Normas de orientação clínica (NOC) sobre terapêuticas destrutivas } \\
& \text { físicas. }\end{aligned}$
\begin{tabular}{l|c|l|c|} 
NOC & Ano & \multicolumn{1}{|c|}{ Conclusões } & NE \\
\hline $\begin{array}{l}\text { National Guideline } \\
\text { Clearinghouse }\end{array}$ & 2008 & $\begin{array}{l}\text { Curetagem por médico experiente e sob } \\
\text { anestesia tópica com lidocaína/prilocaína } \\
20-30 \text { minutos antes do procedimento } \\
\text { (atribuída força recomendação B) }\end{array}$ & 3 \\
\hline EBM Guidelines & 2009 & $\begin{array}{l}\text { A mesma recomendação que a anterior. } \\
\text { (atribuída força recomendação B) }\end{array}$ & 1 \\
\hline
\end{tabular}

Legenda: EBM - Evidence Based Medicine; NE - Nível de evidência.

to mais rápido, mas apresenta mais efeitos adversos do que o imiquimod. (Quadro II)

\section{CONCLUSÕES}

Os resultados obtidos apresentam evidência limitada para a recomendação de intervenção terapêutica no molusco contagioso na idade pediátrica.

Todos os estudos avaliam a eficácia das terapêuticas instituídas mas nem todos analisam os efeitos secundários. Apenas seis ensaios clíni-

Clearinghouse 4 recomenda a realização de curetagem por um médico experiente e sob anestesia tópica com creme de lidocaína/prilocaína, 20-30 minutos antes do procedimento, com força de recomendação B.

A mesma recomendação é emitida pela Evidence Based Medicine Guidelines, ${ }^{5}$ com a mesma força de recomendação (B). (Quadro V)

\subsection{Revisão Sistemática}

Como já referido na parte referente à terapêutica tópica, o estudo Hanna $2006^{11}$ compara as quatro intervenções: curetagem e três terapêuticas tópicas (cantaridina, ácido salicilico e imiquimod 5\%). A curetagem foi a intervenção mais eficaz e com menos efeitos adversos. (Quadro II)

\subsection{Ensaio clínico aleatorizado}

No estudo Al-Mutairi $2010^{17}$ (também já discutido na secção de terapêutica tópica) é comparada a intervenção imiquimod creme $5 \%$ com a crioterapia. Esta última apresentou eficácia superior nas $3^{\mathrm{a}} \mathrm{e} 6^{\mathrm{a}}$ semanas, mas eficácia semelhante nas $12^{\mathrm{a}} \mathrm{e} 16^{\mathrm{a}}$ semanas. A crioterapia tem efei- cos fazem a comparação de uma intervenção terapêutica com placebo. Um deles, Leslie $2005,{ }^{12}$ também inclui uma comparação com outra terapêutica (ácido salicílico versus fenol em álcool $70 \%$ versus veículo - álcool 70\%). Estes resultados limitam a capacidade de atribuição de uma força de recomendação.

A única terapêutica tópica comparada com um controlo, com eficácia comprovadamente superior foi o óleo de mirtilo-limão - força de recomendação B.

Todas as outras terapêuticas mostraram alguma eficácia mas, com excepção dos estudos Saryazdi $2004^{13} \mathrm{e} \mathrm{Han-}$ na 2006, ${ }^{11}$ mais nenhum estudo apresentou eficácia comprovadamente superior em relação a uma terapêutica específica. No estudo comparativo do peróxido de benzoílo com tretinoína (Saryazdi 2004), ${ }^{13}$ apesar de eficácia superior e estatisticamente significativa do peróxido de benzoílo, não existe mais nenhum estudo que o compare com placebo ou controlo - força de recomendação C.

$\mathrm{O}$ imiquimod e a cantaridina são recomendados pela National Guideline Clearinghouse ${ }^{4}$ - força de recomendação C. As restantes terapêuticas tópicas não apresentam evidência suficiente para serem recomendadas no trata- 


\begin{tabular}{|c|c|c|c|}
\hline Terapêuticas & Fundamento & $\begin{array}{l}\text { Nível de } \\
\text { evidência }\end{array}$ & $\begin{array}{c}\text { Força de } \\
\text { recomendação }\end{array}$ \\
\hline Extrato de folha de mirtilo-limão & Burke 2004 & 2 & B \\
\hline Curetagem & $\begin{array}{l}\text { EBM (B) } \\
\text { NGC (B) } \\
\text { Hanna } 2006\end{array}$ & $\begin{array}{l}1 \\
3 \\
2\end{array}$ & B \\
\hline Peróxido de benzoílo & Saryazdi 2004 & 2 & C \\
\hline Imiquimod & $\begin{array}{l}\text { NGC }(B) \\
\text { Theos } 2004 \\
\text { Hanna } 2006 \\
\text { Al-Mutairi } 2010\end{array}$ & $\begin{array}{l}3 \\
2 \\
2 \\
2\end{array}$ & C \\
\hline Cantaridina & $\begin{array}{l}\text { NGC (B) } \\
\text { Hanna } 2006\end{array}$ & $\begin{array}{l}3 \\
2\end{array}$ & C \\
\hline Cimetidina & $\begin{array}{l}\text { NGC (C) } \\
\text { Antony } 2001\end{array}$ & $\begin{array}{l}3 \\
2\end{array}$ & C \\
\hline Crioterapia & Al Mutairi 2010 & 2 & C \\
\hline Hidróxido de potássio & $\begin{array}{l}\text { Bazza } 2007 \\
\text { Short 2002,2006 }\end{array}$ & $\begin{array}{l}2 \\
2 \\
\end{array}$ & \multirow{4}{*}{$\begin{array}{c}\text { Sem evidência } \\
\text { para emitir } \\
\text { recomendação }\end{array}$} \\
\hline Ácido salicílico & $\begin{array}{l}\text { Hanna } 2006 \\
\text { Leslie } 2005\end{array}$ & $\begin{array}{l}3 \\
2\end{array}$ & \\
\hline Fenol & Leslie 2005 & 2 & \\
\hline Tretinoína & Saryazdi 2004 & 2 & \\
\hline
\end{tabular}

Legenda: EBM - Evidence Based Medicine; NGC - National Guideline Clearinghouse.

São necessários mais estudos aleatorizados, duplamente cegos, prospectivos, com amostras relevantes, sobre as diferentes opções terapêuticas versus placebo ou atitude expectante. Em futuros estudos seria igualmente interessante considerar outros outcomes para além da eficácia e eventuais efeitos adversos, como por exemplo, avaliar a ansiedade e grau de satisfação das crianças e dos pais.

Na ausência de evidência robusta sobre a eficácia e segurança dos tratamentos, a atitude expectante deve ser uma estratégia a considerar. $^{1-6}$ São dadas recomendações no sentido da monitorização e educação para minimizar o risco de autoinoculação, nomeadamente não traumatizar as lesões (não coçar, espremer), não partilhar toalhas, banheiras e limitar o contacto directo. ${ }^{4}$

Contudo, a decisão de iniciar terapêutica deve ser individualizada consoante o paciente e a família, tendo em conta a sintomatologia e a extensão das lesões, a duração da doença, as patologias médicas asso-

mento do molusco contagioso na idade pediátrica.

Relativamente à terapêutica sistémica com cimetidina, esta não mostrou ser mais eficaz que o placebo no tratamento do molusco contagioso com efeitos adversos frequentes, mas é recomendada pela National Guideline Clearinghouse $e^{4}$ - força de recomendação C.

Na terapêutica destrutiva física, como já referido anteriormente, no estudo Hanna 2006, a curetagem foi mais eficaz e com menos efeitos adversos que as terapêuticas tópicas comparadas. É também recomendada pela National

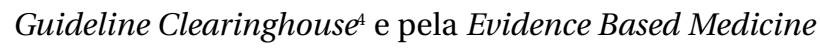
Guidelines, ${ }^{5}$ mas sempre associada a terapêutica tópica analgésica - força de recomendação B.

A crioterapia só é comparada num estudo ${ }^{17}$ com o imiquimod, apresentando eficácia superior e estatisticamente significativa na $3^{\mathrm{a}}$ e $6^{\mathrm{a}}$ semanas; no entanto, também apresenta vários efeitos adversos estatisticamente significativos - força de recomendação C. ciadas e a capacidade da criança e dos pais tolerarem e aderirem às recomendações gerais. ${ }^{1}$

\section{REFERÊNCIAS BIBLIOGRÁFICAS}

1. van der Wouden JC, van der Sande R, van Suijlekom-Smit LW, Berger M, Butler CC, Koning S. Interventions for cutaneous molluscum contagiosum. Cochrane Database Syst Rev 2009 Oct; (4): CD004767.

2. DynaMed [Internet]. Ipswich (MA): EBSCO Publishing. Molluscum contagiosum. Disponível em: http://web.ebscohost.com/login.aspx?ditect=true\&site0Dynamed\&id=113862. [acedido em 25/06/2011].

3. Richardson M, Elliman D, Maguire H, Simpson J, Nicoll A. Evidence base of incubation periods, periods of infectiousness and exclusion policies for the control of communicable diseases in schools and preschools. Pediatr Infect Dis J 2001 Apr; 20 (4): 380-91.

4. University of Texas, School of Nursing, Family Nurse Practitioner Program. Management of molluscum contagiosum. Austin (TX): University of Texas, School of Nursing; 2008.

5. EBM Guidelines [Internet]. 2011 Duodecim Medical Publications Ltd; Molluscum Contagiosum; Article ID: ebm00277 (013.031). Disponível em: http://www.ebm-guidelines.com/go/ebm/ebm00277.html [acedido em 17/05/2009]. 
6. Hanson D, Diven DG. Molluscum contagiosum. Dermatol Online J 2003 Mar; 9 (2): 2 .

7. Ebell MH, Siwek J, Weiss BD, Woolf SH, Susman J, Ewigman B, et al. Strength of recommendation taxonomy (SORT): a patient-centered approach to grading evidence in the medical literature. Am Fam Physician 2004 Feb 1; 69 (3): 548-56.

8. Antony F, Cliff S,Ahmad A, Holden C. Double-blind placebo-controlled study of oral cimetidine treatment for molluscum contagiosum. Br J Dermatol 2001 Jul; 145 Suppl 59: 126.

9. Bazza MA, Ryatt KS. Sterile normal $0,9 \%$ saline as a effective $5 \%$ potassium hydroxide in treatment of molluscum contagiosum, and safer. 2007 May. (unpublished data only).

10. Burke BE, Baillie JE, Olson RD. Essential oil of Australian lemon myrtle (Backhousia citriodora) in the treatment of molluscum contagiosum in children. Biomed Pharmacother 2004 May; 58 (4): 245-7.

11. Hanna D, Hatami A, Powell J, Marcoux D, Maari C, Savard P, et al. A prospective randomized trial comparing the efficacy and adverse effects of four recognized treatments of molluscum contagiosum in children. Pediatr Dermatol 2006 Nov-Dec; 23 (6): 574-9.

12. Leslie KS, Dootson G, Sterling JC. Topical salicylic acid gel as a treatment for molluscum contagiosum in children. J Dermatol Treat 2005; 16 (5-6): 336-40.

13. Saryazdi $S$. The comparative efficacy of benzoyl peroxide $10 \%$ cream and tretinoin $0,05 \%$ cream in the treatment of molluscum contagiosum. Abstract 10th World Congress in Pediatric Dermatology. Pediatr Dermatol 2004 May-Jun; 21 (3): 399.

14. Short KA, Fuller LC, Higgins EM. Double-blind, randomized, placebo-controlled trial of the use of topical $10 \%$ potassium hydroxide solution in the treatment of molluscum contagiosum. Br J Dermatol 2006 May-Jun; 23 (3): 279-81.

15. TheosAU, Cummins R, Silverberg NB, Paller AS. Effectiveness of imiquimod cream $5 \%$ for treating childhood molluscum contagiosum in a double-blind, randomized pilot trial. Cutis 2004 Aug; 74 (2): 134-8, 141-2.

16. Short KA, Fuller LC, Higgins EM. Double-blind, randomized, placebo-controlled trial of the use of topical potassium hydroxide in the treatment of molluscum contagiosum. Br J Dermatol 2002 Jul; 147 Suppl 62: 95.

17. Al-Mutairi N, Al-Doukhi A, Al-Farag S, Al-Haddad A. Comparative study on the efficacy, safety, and acceptability of imiquimod $5 \%$ cream versus cryotherapy for molluscum contagiosum in children. Pediatr Dermatol 2010 Jul-Aug; 27 (4): 388-94.

\section{CONFLITOS DE INTERESSE}

As autoras declaram não possuir conflitos de interesse nem financiamento do estudo.

\author{
ENDEREÇO PARA CORRESPONDÊNCIA \\ Maria Ana Gaspar \\ R. Frei Joaquim Santa Rosa de Viterbo $N^{\circ} 3,7^{\circ}$ Esq \\ 1600-230 Lisboa \\ E-mail:mariaana82@gmail.com
}

Recebido em 01/12/2011

Aceite para publicação em 27/05/2012

\section{ABSTRACT}

\section{TREATMENT OF MOLLUSCUM CONTAGIOSUM IN CHILDREN: AN EVIDENCE-BASED REVIEW}

Introduction: Molluscum contagiosum is a viral skin infection most frequently encountered in children between the ages of 2 and 5 years. In most cases the disease is self-limiting and resolves within 6 months to 2 years, but it may persist for up to 5 years. Treatment is given to relieve symptoms, to control the spread of lesions, to prevent scarring and secondary infection, and for cosmetic and social reasons.

Aim: To assess the evidence for the efficacy and adverse events of treatments for molluscum contagiosum in immunocompetent children. Data sources: Medline, Cochrane Library, Dynamed, National Guideline Clearinghouse and evidence based medicine guidelines.

Review methods: We performed a survey of clinical guidelines, systematic reviews, meta-analysis and clinical trials of treatment of molluscum contagiosum, published between January 2001 and September 2011, in Portuguese, English, French and Spanish, for children aged 18 years old or younger, using the MeSH term molluscum contagiosum. Exclusion criteria: sexually transmitted molluscum contagiosum and immunocompromised children. The SORT (Strength of Recommendation Taxonomy) scale of the American Family Physician was used to grade the evidence.

Results: Twenty-two studies were found. We selected two guidelines, one systematic review, one Dynamed summary and one randomized clinical trial for this review. There is evidence of efficacy with few adverse effects for topical treatment with Australian lemon myrtle oil or for curettage of lesions (strength of recommendation B). For topical treatments with benzoyl peroxide, imiquimod and cantharidin, the evidence is weaker, as well as for systemic treatment with cimetidine and physical destruction of the lesions with cryotherapy (strength of recommendation C). No other evidence-based recommendations can be given for other treatments assessed.

Conclusions: There is limited evidence to recommend treatment of molluscum contagiosum in children. Additional well-designed, prospective studies are needed on therapeutic options compared to placebo or watchful waiting. Without good evidence for the efficacy and safety of treatment, watchful waiting must be considered.

Key-words: Molluscum contagiosum; Therapeutics. 